\title{
Valorização do professor da educação básica e as metas do PNE: um estudo do caso de Piraquara/ PR
}

\author{
Basic education teachers' appreciation and the PNE goals: \\ a case study from Piraquara/PR \\ Valoración del profesor de educación básica y los objetivos del PNE: \\ un estudio de caso de Piraquara/ PR
}

\author{
DANIELE MEIRA CORDEIRO \\ https://orcid.org/0000-0002-5845-8028 \\ Universidade Federal do Paraná \\ Faculdade de Educação \\ Departamento de Políticas Educacionais \\ Piraquara, PR, Brasil \\ ANDRÉA BARBOSA GOUVEIA \\ https://orcid.org/0000-0002-8260-2720 \\ Universidade Federal do Paraná \\ Faculdade de Educação \\ Departamento de Políticas Educacionais
}

Paraná, PR, Brasil

\begin{abstract}
Resumo: Este artigo problematiza as condições de valorização dos professores, a partir das metas do Plano Nacional de Educação (PNE) 2014-2024 e do Plano Municipal de Educação (PME), em um município com baixo desenvolvimento econômico e alta dependência do FUNDEB, mas que apresenta um Plano de Cargos, Carreira e Remuneração (PCCR) estruturado. Objetivou-se analisar as condições de remuneração e formação previstas no PCCR e a efetividade do preceito constitucional da valorização. $\mathrm{O}$ estudo de caso privilegiou a análise documental cotejada com dados do Censo Escolar, SIOPE e RAIS. Os resultados exploram avanços e impasses na formulação do PME e valorização dos professores.
\end{abstract}

Palavras-chave: Políticas Educacionais; Valorização dos professores; PNE; PME.

\begin{abstract}
This article discusses the conditions for valuing teachers, based on the goals of the National Education Plan (PNE) 2014-2024 and the Municipal Education Plan (PME), in a municipality with low economic development and high dependence on FUNDEB, but which presents a structured Positions, Career and Compensation Plan (PCCR). The objective was to analyze the conditions of remuneration and training provided by the PCCR and the effectiveness of the constitutional precept of valuation. The case study privileged the documentary analysis collated with data from the School Census, SIOPE, and RAIS. The results explore advances and impasses in the formulation of the $S M E$ and the appreciation of teachers.
\end{abstract}

Keywords: Educational Policies; Valuing teachers; PNE; SMEs. 
Resumen: En este articulo se analizan las condiciones para la valoración del profesorado, a partir de las metas del Plan Nacional de Educación (PNE) 2014-2024 y del Plan Municipal de Educación (PME), en un municipio con bajo desarrollo económico y alta dependencia de FUNDEB, pero que presenta un Plan estructurado de Posiciones, Carrera y Compensación (PCCR). El objetivo fue analizar las condiciones de remuneración y capacitación previstas en el PCCR y la vigencia del precepto constitucional de tasación. El estudio de caso privilegió el análisis documental cotejado con datos del Censo Escolar, SIOPE y RAIS. Los resultados exploran avances e impases en la formulación de la PYME y la valoración de los docentes.

Palabras clave: Politicas educativas; de los profesores; PNE; PYMES.

\section{INTRODUÇÃO}

Este artigo propõe uma análise das condições de valorização do professor da Educação Básica no contexto municipal. Para isto, tem como foco o estudo do caso de Piraquara, município paranaense, localizado na região metropolitana de Curitiba. Toma como questão de fundo a avaliação das metas do Plano Nacional de Educação 2014-2024, relativas à formação (metas 15 e 16), remuneração (meta 17) e carreira (meta 18). Considerando a importância do planejamento no contexto das políticas educacionais brasileiras (DOURADO, 2017) e os desafios federativos para efetividade do planejamento em cada um dos municípios no país, propõe-se analisar o caso de Piraquara (DUARTE, 2008), município paranaense com baixo desenvolvimento econômico e alta dependência dos recursos do FUNDEB. Em 2018, a rede municipal de ensino atendeu em 10.979 estudantes matriculados na Educação Infantil e nas séries iniciais do Ensino Fundamental e Educação de Jovens e Adultos. A análise privilegia a efetividade do Plano de Carreira, as condições de remuneração municipal e o perfil dos professores, especificamente em relação à formação. A metodologia privilegiou a análise documental (CELLARD, 2008) do Plano Municipal de Educação e o cotejamento das metas do plano com fontes de dados sobre perfil de formação, para o que se utilizou o Censo Escolar; sobre remuneração utilizou a fonte SIOPE e para a comparação com outras ocupações no âmbito municipal, utilizou-se como fonte a Relação de Informações Sociais (RAIS). O cotejamento de dados de formação, remuneração e condições de trabalho decorre da revisão de literatura na área que evidencia estes aspectos como basilares para a efetividade do preceito constitucional de valorização do magistério (GROCHOSKA, 2015; HECK, 2019). Para isto, o artigo conta com três sessões: a primeira apresenta os elementos conceituais para análise da responsabilidade municipal em relação ao trabalho docente; a segunda sessão apresenta um panorama do PNE e o contexto do PME de Piraquara; 
a terceira sessão coteja os dados, especificamente dos professores, a partir das diferentes fontes, procurando avaliar a efetividade das metas do PNE e do PME no contexto municipal e mapear os principais desafios.

\section{CONTEXTO DE FINANCIAMENTO DA EDUCAÇÃO MUNICIPAL E OS DESAFIOS DA VALORIZAÇÃO DOCENTE}

A Constituição Federal de 1988, com suas 108 Emendas aprovadas até 2020, define a divisão de responsabilidades pela oferta educacional no Brasil e institui os municípios como responsáveis pela garantia do Ensino Fundamental e da Educação Infantil e, ao mesmo tempo, define o patamar mínimo de investimento em Manutenção e Desenvolvimento do Ensino (MDE), estabelecendo uma vinculação constitucional de $25 \%$ da receita de impostos e transferências. Essas são duas ideias fortes que situam constitucionalmente a ação municipal em relação ao direito à educação. A explicitação das responsabilidades e condições municipais para garantia da educação em 1988, ainda que tenha contribuído com o fortalecimento dos sistemas municipais de ensino, se fez num contexto federativo desigual e continua significando um desafio para a qualidade da oferta educacional no país.

Há ampla literatura no campo do financiamento da educação, destacando as desigualdades em termos de capacidade tributária e seus efeitos nas condições de oferta educacional em relação à infraestrutura (PINTO, 2009; ARAÚJO, 2019) e às condições de remuneração de professores (ALVES;PINTO, 2011; SILVA, 2019; FERNANDES; FERNANDES, 2020;) que permitem indicar que a ampliação de recursos para educação no país é condição fundamental para ampliação da qualidade educacional. Esta perspectiva foi inscrita no PNE 20142024 como meta de ampliação de investimentos em educação com vistas a que, no final da década, o país pudesse investir o equivalente a 10\% na área.

A política de fundos vigente nas últimas décadas, entre 1997 e 2006, o Fundo de Manutenção e Desenvolvimento do Ensino Fundamental e de Valorização do Magistério (FUNDEF) e, entre 2007 até 2021, o Fundo de Manutenção e Desenvolvimento da Educação Básica e de Valorização dos Profissionais da Educação (FUNDEB) têm contribuído para a diminuição das desigualdades, especialmente internas aos estados da federação, e, de maneira mais fraca têm diminuído as desigualdades nacionais. Pode-se destacar que o aumento do patamar de complementação da União no contexto do FUNDEB foi instrumento relevante para este movimento. Este papel crucial da União está expresso nas metas do PNE e na defesa do FUNDEB permanente, aprovado em 2020, por meio da Emenda Constitucional 108. Destaca-se que a luta pela 
ampliação da participação da União, dos atuais 10\% de contribuição para $40 \%$, de forma a assegurar outro patamar de financiamento da educação com qualidade e equidade, tem sido defendido por meio de manifestos e campanhas por diferentes movimentos sociais, resultando no aumento para 23\% da receita. (CNTE, 2019; CAMPANHA, 2019; FINEDUCA, 2019; ANPED; 2019). Apesar de menor do que o proposto pelos movimentos, o novo patamar representa o dobro do previsto durante o período de vigência do FUNDEB. As mudanças nas regras de redistribuição do fundo ainda demandam regulamentação e poderão beneficiar estados e municípios que até agora não tinham complementação da União.

No contexto da política de fundos, o tema da valorização do magistério é relevante, dado que entre os objetivos, tanto do FUNDEF quanto do FUNDEB, está a necessidade de assegurar remuneração condigna aos profissionais (BRASIL, 1996; BRASIL, 2007). E, entre as regras de aplicação dos recursos dos fundos, os entes federados ficam obrigados a garantir a destinação de, pelo menos, $60 \%$ da receita efetivada na remuneração de professores. Este mecanismo, entretanto, mesmo ao fixar um percentual, não avança na definição de um patamar digno de remuneração.

Neste sentido, a aprovação da Lei do Piso Salarial Profissional Nacional (PSPN) foi um elemento importante para a explicitação da necessidade de uma política nacional que fixe a referência de remuneração digna. Ainda que haja problemas quanto ao cumprimento do PSPN (GOUVEIA; FERNANDES, 2019; COSTA; COELHO, OLIVEIRA, 2020), a legislação nacional definiu um horizonte de reivindicações com um valor mínimo abaixo do qual nenhum profissional do magistério deve ser contratado, articulando remuneração à jornada e à formação, elementos que são centrais na definição da valorização do magistério e basilares na estrutura da carreira. Além disto, é relevante na disputa pela garantia da valorização profissional, o reconhecimento na lei de que o valor precisa ser reajustado anualmente. Para isto, a lei do PSPN definiu como parâmetro de reajuste anual do piso, o crescimento do valor anual do FUNDEB, o que poderia garantir uma valorização real dos vencimentos iniciais dos profissionais, entretanto, este mecanismo ainda precisa ser articulado aos desenhos e ao cumprimento dos Planos de Carreira para garantir que os efeitos atinjam o conjunto dos profissionais da educação.

A partir destes elementos de fundo propõe-se analisar o cenário de um município paranaense onde os recursos do FUNDEB são fundamentais nas finanças públicas e onde há um plano de carreira em execução que cumpre os requisitos mínimos da lei do PSPN, no que diz respeito ao vencimento inicial 
e a reajustes anuais. Portanto, problematiza-se o alcance destas políticas para o cumprimento dos compromissos de longo prazo para a educação, expressos no PNE e no PME.

\section{AS METAS DE VALORIZAÇÃO DOS PROFESSORES NO PNE 2014-2024 E O CONTEXTO DO PME DE PIRAQUARA}

O Plano Nacional de Educação está preconizado na Constituição Federal de 1988 e na Lei de Diretrizes e Bases da Educação Nacional (LDB 9394/96). Essa visibilidade jurídica, apresentada nas principais legislações nacionais, responde a uma demanda social pelo direito à educação. Sua característica enquanto projeto coletivo, bem como sua duração decenal, de certo modo, perpassam diferentes gestões e grupos políticos e se tornam uma importante ferramenta na elaboração dos planos de governo, portanto, deve ser fortalecido enquanto uma política pública de estado que esteja pautada na cidadania e na justiça social (OGIBA, 2018).

Atualmente, está vigente a Lei Federal no 13.005 de 25 de junho de 2014, que aprova o PNE 2014-2024 e estabelece diretrizes, metas e estratégias para a educação brasileira. Na busca por um Sistema Nacional de Educação (SNE) e no alinhamento entre metas nacionais, estaduais e municipais, a referida lei determinou que Municípios e Estados teriam o prazo de um ano, a partir da data publicação da lei, para elaborarem seus Planos Estaduais (PEE) e Planos Municipais de Educação (PME) (BRASIL, 2014). Assim, os Planos Municipais e Estaduais respondem a uma tentativa de mobilizar Estados e Municípios, para que, de maneira articulada com as diretrizes e estratégias do PNE, atinjam metas locais que contribuam para o cumprimento das metas nacionais.

Todavia, é importante ressaltar que mobilizar 26 Estados, Distrito Federal e mais os 5.570 municípios do país não é uma tarefa simples, envolve disputa de poder e força política, mesmo o PNE determinando que "Os processos de elaboração e adequação dos planos de educação dos Estados, do Distrito Federal e dos Municípios [...], serão realizados com ampla participação de representantes da comunidade educacional e da sociedade civil.” (BRASIL, 2014). Este processo, além de ser complexo no momento inicial de elaboração, é também desafiador no que se refere à implementação e à avaliação dos planos.

No caso do município de Piraquara, o PME foi elaborado coletivamente num processo democrático de participação representativa dos diferentes segmentos que compõem o quadro de servidores da educação municipal, como o próprio documento afirma: 
A Secretaria Municipal de Educação (SMED) e o Conselho Municipal de Educação (CME) assumiram a coordenação do processo de elaboração do PME, promovendo as seguintes ações: realização de reuniões com a comissão instituída para acompanhar o processo de elaboração do PME; constituição de uma equipe técnica para direcionar os trabalhos; composição e realização de grupos de estudos e trabalhos com representantes de professores/as, trabalhadores da educação e sociedade civil organizada; promoção de estudos e discussões coletivas nas instituições de ensino; realização de audiência pública para divulgação e aprovação do documento-base do PME. (PIRAQUARA, 2015).

As discussões iniciaram logo após a aprovação do Plano Nacional de Educação, em 2014, e o texto final foi aprovado por meio da Lei Municipal $\mathrm{n}^{\circ}$ 1491/2015. É importante ressaltar que a redação das metas, em sua maioria, se manteve igual às aprovadas no PNE, apenas as estratégias foram adaptadas em face à conjuntura municipal. $\mathrm{O}$ fato do município não adaptar a redação das metas locais gera implicações no acompanhamento e monitoramento do PME e dificulta o mapeamento das possibilidades e dos desafios a serem elencados nas estratégias.

Após essa breve contextualização do PNE e do PME do município de Piraquara, cabe adentrar especificamente na análise das condições de valorização expressas em ambos os planos de educação. A partir de elementos das legislações nacionais (CF/88, LDB 9394/96, FUNDEB, Lei n ${ }^{\circ} 11738 / 2008$ ) e fundamentado no conceito de valorização docente proposto por Grochoska $(2015)^{1}$, considerase nesse estudo, que os parâmetros para definir as condições de valorização do professor podem ser pensados com base nos três eixos estruturantes da carreira, sendo eles: formação, remuneração e condições de trabalho. Logo, é necessário considerar se a estrutura da carreira docente possibilita condições objetivas de valorização, por meio da articulação desses três eixos.

Além de ser uma das diretrizes do PNE 2014-2024, a valorização dos profissionais da educação se desdobra em um bloco de quatro metas, sintetizadas no Quadro 1:

1 Grochoska define valorização nos seguintes termos: Um princípio constitucional que se efetiva por meio de um mecanismo legal chamado carreira, que se desenvolve por meio de três elementos, sendo: a) formação, b) condições de trabalho e c) remuneração, tendo como objetivos a qualidade da educação e a qualidade de vida do trabalhador. (GROCHOSKA, 2015, p. 28). 


\section{Quadro 1 - Metas do PNE 2014-2024, voltadas para a valorização dos profissionais da educação}

\begin{tabular}{|c|c|l|c|}
\hline META & EIXO & \multicolumn{1}{|c|}{ OBJETIVO } & PRAZO \\
\hline 15 & $\begin{array}{c}\text { Formação } \\
\text { inicial }\end{array}$ & $\begin{array}{l}\text { Garantir, em regime de colaboração, a Política Nacional de } \\
\text { Formação de Professores, como forma de assegurar que todos os } \\
\text { professores da Educação Básica possuam formação especifica em } \\
\text { Nível Superior, na área em que atuam. }\end{array}$ & $\begin{array}{c}1 \text { (um) ano após a aprovação } \\
\text { do PNE (2015). }\end{array}$ \\
\hline 16 & $\begin{array}{c}\text { Formação } \\
\text { Continuada }\end{array}$ & $\begin{array}{l}\text { Formar, em nível de pós-graduação, no mínimo 50\% dos professores } \\
\text { da Educação Básica e garantir Formação Continuada para todos os } \\
\text { profissionais da educação. }\end{array}$ & $\begin{array}{c}\text { Até o final da vigência do PNE } \\
\text { (2024). }\end{array}$ \\
\hline 17 & Remuneração & $\begin{array}{l}\text { Valorizar os professores por meio da equiparação salarial, em } \\
\text { relação a outros profissionais com o mesmo nível de formação. }\end{array}$ & $\begin{array}{c}\text { Até o final do sexto ano de } \\
\text { vigência do PNE (2020). }\end{array}$ \\
\hline 18 & Carreira & $\begin{array}{l}\text { Assegurar a existência de planos de carreira para todos os } \\
\text { profissionais da educação. }\end{array}$ & $\begin{array}{c}\text { 2 (dois) anos após a } \\
\text { aprovação do PNE (2016). }\end{array}$ \\
\hline
\end{tabular}

Fonte: BRASIL (2014).

É a partir desse bloco de metas que se desenvolverá a análise do PME de Piraquara e o cotejamento com a realidade municipal. Conforme dito anteriormente, como as metas municipais foram pouco alteradas, torna-se relevante dar atenção às estratégias.

No caso da meta dedicada à formação inicial, a estratégia 15.1 do PME busca assegurar que todos os professores possuam formação específica em nível superior, todavia, o plano de carreira do município ainda admite o ingresso na carreira com nível médio, na modalidade normal. Dessa forma, na estrutura da carreira municipal e por meio da tabela salarial, a valorização da formação em nível superior se dá com a elevação do nível I para o nível II, que representa um crescimento de 50\% em relação ao vencimento inicial do nível I. Vale destacar que o professor que ingressa na rede, mesmo que possua formação em nível superior, só passará a receber de acordo com sua formação/titulação, após o período do estágio probatório, que tem duração de três anos. Portanto, ao mesmo tempo em que o professor com formação em nível médio na modalidade normal, que conclui sua graduação e eleva 50\% na tabela salarial sente-se valorizado e reconhecido pela sua formação, o professor que ingressa na carreira com graduação ou pósgraduação não se sente igualmente valorizado, visto que, durante três anos terá o vencimento referente ao de nível médio - normal, ou seja, terá sua formação valorizada, ao menos em termos salariais, apenas passado o período de estágio probatório.

A meta 16 do PME de Piraquara difere da meta nacional quando não estipula uma porcentagem de professores a serem formados, em nível de pósgraduação, e determina: "Estimular os professores/as na busca de formação em nível de pós-graduação stricto sensu (...)” (PIRAQUARA, 2015). As estratégias da meta não apresentam mecanismos concretos e específicos sobre a pós-graduação 
lato e stricto sensu. Em relação à formação continuada, que é contemplada na meta nacional e local, uma das estratégias do PME propõe que a Secretaria Municipal de Educação oferte a carga horária anual de $60 \mathrm{~h}$ de formação continuada aos professores, o que está estabelecido no plano de carreira desde 2012.

Apenas duas estratégias compõem a meta 17 do PME. A primeira, busca garantir o cumprimento do PSPN e assegurar os ganhos remuneratórios entre os níveis da tabela salarial. E a segunda, tem o objetivo equiparar o rendimento médio dos professores aos demais profissionais com escolaridade equivalente até o quinto ano de vigência do PME, um ano a menos do que o estabelecido na meta nacional.

Em relação à meta 18, as estratégias do PME de Piraquara estão voltadas para o cumprimento integral do Plano de Carreira do Magistério (Lei Municipal $\left.n^{\circ} 1192 / 2012\right)$, e propõem a elaboração de um plano de carreira para os demais trabalhadores em educação, o qual foi aprovado por meio de lei municipal, dois anos após o PME.

Formação inicial e continuada, remuneração e carreira são elementos basilares e concretos para as condições de valorização e estão sintetizados nessas quatro metas do PNE e do PME de Piraquara, mesmo assim, ainda representam desafios às políticas educacionais pela questão da demanda de ampliação de financiamento da educação, sobretudo, após aprovação da Emenda Constitucional (EC) 95/2016, que propõe um Novo Regime Fiscal (NRF), marcado por uma política de ajuste econômico em que impera a redução do papel do Estado e impede o avanço de políticas públicas voltadas para a diminuição das desigualdades sociais (AMARAL, 2017).

A EC, com duração de vinte exercícios financeiros, a contar de 2017, limita os gastos públicos primários do Orçamento do Executivo Federal e altera a lógica dos investimentos em educação, pois enfraquece a vinculação constitucional de recursos ao definir que as aplicações mínimas em Manutenção e Desenvolvimento do Ensino (MDE) sejam definidas pelo montante gasto no ano anterior, reajustado pela inflação medida pelo Índice Nacional de Preços ao Consumidor Amplo (IPCA) (BRASIL, 2016), rompendo assim, com a porcentagem estabelecida da receita de impostos, de $18 \%$ para a União e $25 \%$ para Estados e Municípios.

Nessa conjuntura, cabe ponderar a possível indução que uma política de austeridade, em nível Federal, pode provocar na efetivação das metas dos Planos Estaduais e Municipais de Educação, uma vez que não haverá o aporte de novos recursos para MDE, o que implica na oferta, na qualidade e, também, na efetivação de políticas de valorização docente, de acordo com o que está previsto 
nos planos de educação (SILVA, FRANÇA, 2017). Assim, pode-se dizer que o $\mathrm{NRF}$ não está alinhado com as metas do $\mathrm{PNE}$, principalmente em relação à meta 20, que prevê o aumento do patamar do PIB para investimentos em educação.

Especificamente sobre a avaliação e monitoramento do PNE, a Lei ${ }^{\circ}$ 13.005 indica que o Instituto Nacional de Estudo e Pesquisas Educacionais Anísio Teixeira (INEP) é o responsável pelo acompanhamento, análise e monitoramento das metas, por meio da elaboração de indicadores para verificar a evolução e o cumprimento destas. Assim, a cada biênio, o INEP deve produzir um relatório, contendo as análises e a evolução das metas. O relatório do primeiro ciclo de monitoramento, referente ao biênio 2014-2016, foi publicado em 2016, já o relatório do segundo ciclo foi publicado em junho de 2018. O monitoramento e acompanhamento é realizado mediante indicadores específicos, conforme expressa o quadro 2:

\section{Quadro 2 - Relatório do $2^{\circ}$ Ciclo de Monitoramento das metas do PNE - 2018}

\begin{tabular}{|c|c|c|c|}
\hline META & INDICADOR & FONTE & ABRANGÊNCIA \\
\hline Meta 15 & $\begin{array}{l}\text { Indicadores de adequação } \\
\text { da formação docente }\end{array}$ & Indicadores do INEP & $\begin{array}{l}\text { Brasil, Grandes Regiões, } \\
\text { Unidades da Federação, } \\
\text { Municípios e Escolas. }\end{array}$ \\
\hline Meta 16 & $\begin{array}{l}\text { Coleta de informações } \\
\text { relacionadas à Formação } \\
\text { Continuada }\end{array}$ & Censo da Educação Básica & $\begin{array}{l}\text { Brasil, Grandes Regiões de } \\
\text { Unidades da Federação. }\end{array}$ \\
\hline Meta 17 & $\begin{array}{l}\text { Rendimento bruto médio } \\
\text { mensal dos profissionais } \\
\text { do magistério e dos demais } \\
\text { profissionais assalariados, } \\
\text { com nível superior. }\end{array}$ & Pnad Contínua - IBGE (Pnad-C) & $\begin{array}{l}\text { Brasil e Unidades da } \\
\text { Federação. }\end{array}$ \\
\hline Meta 18 & $\begin{array}{l}\text { Existência de PCR e } \\
\text { cumprimento da Lei } \\
11738 / 2008 \text { (jornada e Piso). }\end{array}$ & Estadic, Munic, Simec. & $\begin{array}{l}\text { Brasil, Unidades de } \\
\text { Federação e Municípios. }\end{array}$ \\
\hline
\end{tabular}

Fonte: BRASIL (2018).

A partir do segundo relatório de monitoramento e utilizando alguns dos indicadores apresentados, realizar-se-á um mapeamento da realidade do PME de Piraquara e dos desafios frente às metas de valorização expressas no PNE. Observe-se que, para o caso da remuneração no âmbito municipal, a Pesquisa Nacional por Amostragem de Domicílio (Pnad) contínua do IBGE não pode ser utilizada, pois não é representativa em nível municipal. Este é um limite do PNE, visto que a comparação não poderá ser feita anualmente para cada município brasileiro. Certamente a resolução desta questão nacionalmente depende de cada um dos planos de carreira de estados e municípios, porém a mudança efetiva na média nacional não é uma soma simples dos casos. 
Neste artigo, optou-se por analisar a movimentação dos dados de remuneração nos anos de 2017 e 2018 a partir da folha de pagamento disponível no Sistema de Informações sobre Orçamentos Públicos em Educação (SIOPE) e comparar as médias de remuneração com outras carreiras municipais, especificamente de 2018, declaradas na Relação Anual de Informações Sociais do Ministério do Trabalho e Emprego (RAIS). A ideia não é efetivamente medir, neste caso, o cumprimento da meta, pois isto é impossível com outros indicadores que não o previsto, mas ilustrar o desafio da valorização docente a partir de alguns parâmetros municipais.

\section{AS CONDIÇÕES DE VALORIZAÇÃO DOS PROFESSORES EM PIRAQUARA E AS METAS DO PNE: REALIDADE E HORIZONTES}

A carreira docente enquanto um princípio constitucionalé um instrumento capaz de promover a valorização por meio de três eixos estruturantes que a constituem e a efetivam: formação, remuneração e condições de trabalho. Logo, a primeira questão a se considerar na análise do contexto municipal é a existência de Plano de Carreira e a sua efetividade pensada em termos de abrangência e de cumprimento de seus dispositivos, posto que apenas possuir uma carreira não resulta em valorização; é necessário que essa carreira seja devidamente estruturada e implementada (GROCHOSKA, 2015), de forma a assegurar a transição dos profissionais entre os níveis e classes previstos, principalmente, por meio do reconhecimento da formação continuada e do tempo de serviço.

Em termos de abrangência, o PCCR de Piraquara garante cobertura aos professores em atuação na Educação Infantil e no Ensino Fundamental e suas modalidades. É positivo o reconhecimento de um único plano para todos os docentes, entretanto, cabe considerar a condição peculiar da Educação Infantil, em que há profissionais que atuam no apoio à docência, denominadas Agentes Educacionais 1, mas que não estão protegidos pelo mesmo plano:

O trabalho desenvolvido com as crianças nos CMEI é realizado, portanto, por profissionais dos cargos de: Professora e Agentes Educacionais I Interação com Educandos. Essa última carreira é destinada a profissionais docentes que, na percepção da gestão municipal, atuam como "auxiliares das professoras". (HECK, 2019, p.87). 
Esta é uma situação bastante presente nos municípios brasileiros (HECK, 2019; NASCIMENTO, 2019) e que torna mais complexa a análise do trabalho docente na Educação Básica, uma vez que o tema da carreira não se esgota na análise das condições dos planos específicos do magistério. Entretanto, apesar deste registro, neste artigo não há condições de estender a análise para estes profissionais.

Estabelecendo paralelo com o Plano Nacional de Educação, tem-se a meta 18, que é específica para assegurar a existência de planos de carreira e toma como referência a lei do PSPN, portanto, a avaliação dessa meta envolve, exclusivamente, os elementos que compõem a lei do Piso Salarial, uma vez que os indicadores utilizados são: a) verificar a existência de planos de carreira nos Estados e Municípios; bem como b) se é cumprida a lei do Piso, no que se refere ao valor da remuneração e também da especificação da jornada de trabalho.

Utilizando esses indicadores, o Relatório do $2^{\circ}$ Ciclo de Monitoramento aponta que, segundo dados da Munic/IBGE 2014, 89,2\% dos municípios possuem plano de carreira e remuneração dos profissionais do magistério da Educação Básica (BRASIL, 2018), apresentando os seguintes dados em relação aos 5.570 municípios brasileiros:

\section{TABELA 1 - Indicadores de monitoramento da meta 18 do PNE - 2014, 2024}

\begin{tabular}{|c|c|}
\hline INDICADOR & NÚMERO DE MUNICIPIOS \\
\hline Cumprem o valor do PISO & 3.687 \\
\hline Respeitam 2/3 da jornada em atividade com o educando & 3.102 \\
\hline Sem informação & 1.253 \\
\hline
\end{tabular}

Fonte: Adaptado do Relatório do $2^{\circ}$ Ciclo de Monitoramento das metas do PNE - 2018.

Piraquara está entre os municípios que possuem plano de carreira e cumpre o valor do PSPN, todavia, ainda não cumpre a lei no que diz respeito à jornada de trabalho. O plano de carreira do município prevê a expansão gradativa da porcentagem de horas trabalhadas destinadas à hora-atividade, pretendendo ultrapassar o que está estabelecido na lei do piso, sendo que, até o ano de 2016, essa porcentagem deveria contemplar 35\% da carga horária semanal. Todavia, na atual realidade municipal, são garantidas $30 \%$ de hora-atividade semanais, não atingindo o mínimo de 1/3 (um terço) estabelecido na lei do piso. Sabe-se que o PSPN não é efetivo em sua integralidade em todos os Estados e Municípios do país (CARISSIMI, 2016). No caso de Piraquara, por se tratar de um município com baixa arrecadação e que depende quase que exclusivamente dos recursos 
provenientes do Fundeb para manter a folha de pagamento ${ }^{2}$ e, portanto, o desenvolvimento da carreira, possivelmente o desafio em ampliar a hora-atividade está relacionado com a necessidade de ampliar as contratações e conseguir manter a estrutura e o desenvolvimento da carreira. Mesmo sabendo das limitações financeiras do município, fazer cumprir a lei $n^{\circ} 11738 / 2008$ na sua integralidade, precisa estar como uma das prioridades da agenda local, uma vez que a lei é de 2008, foi reforçada no plano de carreira de 2012 e no PME de 2015.

Em relação à remuneração dos professores nos termos da lei do piso, foram consultados os dados da folha de pagamento disponibilizados no SIOPE e as tabelas de vencimento do quadro do magistério do PCCR de Piraquara. Os dados estão organizados na tabela 2:

\section{Tabela 2 - Média da remuneração dos professores na rede municipal de ensino de Piraquara em relação ao PSPN}

\begin{tabular}{|c|c|c|c|c|c|}
\hline Ano & Valor do PSPN - 40h & $\begin{array}{c}\text { PSPN } \\
\text { proporcional 20h }\end{array}$ & $\begin{array}{c}\text { Vencimento inicial para } \\
\text { Nível Médio - 20h }\end{array}$ & $\begin{array}{c}\text { Média da } \\
\text { remuneração para } \\
\text { Nivel Médio - 20h }\end{array}$ & $\begin{array}{c}\text { Variação entre } \\
\text { o vencimento } \\
\text { inicial e a média } \\
\text { da remuneração }\end{array}$ \\
\hline 2017 & $\mathrm{R} \$ 2.298,80$ & $\mathrm{R} \$ 1.149,40$ & $\mathrm{R} \$ 1.149,55$ & $\mathrm{R} \$ 1.386,25$ & $20,59 \%$ \\
\hline 2018 & $\mathrm{R} \$ 2.455,35$ & $\mathrm{R} \$ 1.227,67$ & $\mathrm{R} \$ 1.227,67$ & $\mathrm{R} \$ 1.630,49$ & $32,81 \%$ \\
\hline
\end{tabular}

Fonte: SIOPE - Dados da Remuneração, 2017, 2018; Tabelas de Vencimento do Quadro do Magistério, Piraquara, 2017, 2018.

Essas informações revelam que em Piraquara nenhum professor apresenta remuneração inferior ao PSPN, visto que o vencimento inicial da tabela salarial é reajustado anualmente de acordo com a atualização do valor do piso nacional. Vale destacar que em muitos municípios a literatura tem constatado que "a obrigação do pagamento desse valor (mínimo) tem resultado em achatamento da carreira, já que a lei não prevê uma diferenciação salarial para os que têm formação superior.” (OLIVEIRA, 2019, p. 293), o que não acontece em Piraquara, devido à organização da tabela salarial que diferencia o vencimento inicial por níveis, de acordo com a formação/titulação. A tabela salarial está organizada de forma que todos os profissionais que ingressam na carreira se mantenham no nível I, referente à formação mínima exigida em nível médio na modalidade normal. Aqui está um desafio da carreira dos professores de Piraquara: ter a formação em nível superior ou pós-graduação, já reconhecidas no início de carreira em termos de remuneração, sem ter que esperar a passagem do período do estágio probatório.

2 Segundo dados do RREO do SIOPE, em 2017 e 2018, o percentual dos recursos do Fundeb aplicado na remuneração do magistério, foi de $82 \%$ e $84 \%$, respectivamente. 
Em contrapartida, após esse período, as elevações de nível de acordo com a formação podem acontecer a qualquer tempo, assim que o professor comprovar a sua formação.

Outro aspecto percebido na tabela 2 é que a porcentagem de variação entre o vencimento inicial e a média da remuneração indica que existe movimentação horizontal na carreira em relação ao tempo de serviço, que em Piraquara também está condicionada à avaliação de desempenho. Ou seja, a média da remuneração é maior que o vencimento inicial no caso de professores que possuem mais de três anos de carreira, devido às progressões entre as subclasses.

Sobre a movimentação horizontal, o plano de carreira garante a progressão de subclasses, com um acréscimo de $2 \%$ anualmente, se o professor obtiver 70 pontos ou mais na sua avaliação de desempenho. Essa efetividade do cumprimento dos dispositivos do PCCR por meio dos procedimentos da avaliação da prática profissional é outro aspecto positivo do caso em análise.

Além disso, a carreira de Piraquara também possibilita a movimentação por meio de formação, após o período do estágio probatório, nos seguintes termos: se o professor possuir licenciatura, passará automaticamente para o nível II; se possuir especialização, progredirá para o nível III; e, se possuir mestrado ou doutorado, passará para o nível IV. Permanecerão no nível I somente os professores com formação em nível médio, na modalidade normal.

O plano de carreira especifica, ainda, as porcentagens de acréscimo no vencimento inicial entre os níveis, a saber: entre o nível I e o nível II: 50\%; entre o nível II e o nível III: 15\%; e entre o nível III e o nível IV: 20\% (PIRAQUARA, 2012). Com isso, no tocante à efetividade dos dispositivos que garantem o desenvolvimento da carreira, o PCCR utiliza a formação e o tempo de serviço, ambos atrelados à avaliação da prática profissional, como dispositivos que possibilitam o desenvolvimento da carreira, de acordo com o disposto no artigo 67 da LDB 9394/96.

Analisar as condições de cumprimento das metas 15 e 16 do PNE e do PME, que se referem à formação dos professores, coloca em questão a opção da entrada na carreira de Piraquara a partir do nível médio na modalidade normal. Esta é formação mínima exigida na legislação nacional, entretanto, esta forma de acesso ao cargo implica um impasse, pois o prazo do PNE para que todos os professores da Educação Básica tenham formação em nível superior era de apenas um ano, porém dada a condição de ingresso e a mudança de nível dos professores apenas ao final do estágio probatório, na prática, sempre poderá haver professores com formação menor que Ensino Superior. Este impasse, na 
verdade, não é exclusivo do caso de Piraquara, mas da legislação nacional. Em termos de avaliação das metas, importa observar o perfil dos professores em exercício no município.

Os dados do Censo Escolar de 2017 e 2018 (Tabela 3) permitem observar que quase $35 \%$ dos professores tinham até o Ensino Médio nos dois anos analisados. É positivo considerar que há crescimento no número de professores com formação superior, especialmente entre os que possuem especialização.

\section{Tabela 3 - Professores por formação na Rede Municipal de Ensino de Piraquara, conforme registro no Censo Escolar}

\begin{tabular}{|c|c|c|c|c|}
\hline \multirow{2}{*}{ FORMAÇÃo } & \multicolumn{2}{|c|}{2017} & \multicolumn{2}{c|}{2018} \\
\cline { 2 - 5 } & $\mathbf{N}$ & $\%$ & $\mathbf{N}$ & \% \\
\hline Ensino Fundamental completo & 1 & 0,22 & 0 & 13,58 \\
\hline Ensino Médio* $^{*}$ & 65 & 14,32 & 66 & 20,16 \\
\hline Ensino Médio na modalidade normal & 93 & 20,48 & 98 & 0,21 \\
\hline Superior bacharelado ou tecnólogo & 2 & 0,44 & 1 & 18,72 \\
\hline Superior licenciatura ou complementação pedagógica & 88 & 19,38 & 91 & 46,91 \\
\hline Especialização com licenciatura & 204 & 44,93 & 228 & 0,41 \\
\hline Mestrado com licenciatura & 1 & 0,22 & 2 & 100,00 \\
\hline Total & 454 & 100,00 & 486 & \\
\hline
\end{tabular}

Fonte: Censo Escolar $(2017 ; 2018)$.

* Informações fornecidas pela Secretaria Municipal de Educação de maneira informal, indicam que não há professor efetivo, com formação inferior a de nível médio na modalidade normal, provavelmente houve equívocos da SME no momento do preenchimento de dados do Censo Escolar.

Se por um lado a formação inicial continua pautada na exigência mínima da legislação, por outro lado chama a atenção a proximidade do cumprimento da meta 16 do PNE, que busca atingir 50\% dos professores com formação em pósgraduação. Trata-se, no caso de Piraquara, como em geral no Brasil, de formação em pós-graduação lato sensu, mas o percentual é maior que a média nacional, que no ano de 2017 era de 36,2\%, conforme apresentado no segundo relatório de monitoramento das metas do PNE (BRASIL, 2018). Em termos de formação em pós-graduação stricto sensu no município de Piraquara, o desafio é significativo, pois o número de professores com mestrado é muito tímido e não há o registro de nenhum professor com doutorado, além disso, não há o registro de estratégias do PME, voltadas para esse nível de formação, e ainda, a tabela salarial não contempla um nível específico para os professores com doutorado, significando que o professor que apresentar essa titulação não poderá elevar sua remuneração. Nos termos de garantia das elevações de nível de acordo com a formação, os 
dados da Tabela 4 demonstram que as porcentagens entre as elevações de nível estabelecidas no plano de carreira estão sendo cumpridas entre os níveis I e II e os níveis II e III, portanto, há uma articulação entre formação e remuneração na maneira como os professores movimentam-se na carreira.

\section{Tabela 4 - Média da remuneração dos professores de Piraquara, de acordo com a formação/titulação}

\begin{tabular}{|c|c|c|c|c|}
\hline \multirow{2}{*}{$\begin{array}{c}\text { Média da } \\
\text { Remuneração }\end{array}$} & R\$ & Diferença entre níveis & R\$ & Diferença entre níveis \\
\cline { 2 - 5 } & 1386,25 & & 1630,49 & \\
\hline Nível Médio - Normal & 2097,33 & $51,3 \%$ & 2534,27 & $55,4 \%$ \\
\hline Licenciatura & 2866,04 & $36,6 \%$ & 3103,50 & $22,4 \%$ \\
\hline Especialização & 3234,58 & $12,8 \%$ & 3551,33 & $14,4 \%$ \\
\hline Mestrado/ Doutorado & &
\end{tabular}

Fonte: SIOPE - Dados da Remuneração, 2017, 2018. Mês de referência: março.

A diferença percentual da média de remuneração entre os níveis III e IV, que representa a elevação de nível entre especialização e mestrado/doutorado, está inferior aos $20 \%$ estabelecidos no plano de carreira, todavia, se observar-se a tabela salarial dos anos de 2017 e 2018, a média da remuneração apresentada na Tabela 4 é superior ao vencimento inicial para professores que possuem mestrado.

Finalmente, o grande desafio, não somente no caso de Piraquara, está na meta 17 , que se refere à equiparação salarial dos professores com profissionais de outras carreiras com mesma formação. Essa meta reflete uma luta histórica dos professores brasileiros e é marcada pela disputa política em torno do seu impacto financeiro (JACOMINI; ALVES; CAMARGO, 2016), uma vez que sua efetivação envolve ampliação de recursos, por isso, a meta 20 indica a necessidade de garantir 10\% do PIB para os recursos da educação.

Considerando os limites de dados para medir esta meta no âmbito municipal, optou-se por um exercício a partir da RAIS de 2018 para uma aproximação com o desafio desta dimensão. A RAIS é um registro administrativo do Ministério do Trabalho e Emprego, realizado pelo empregador. Há muitos desafios no trabalho com os dados da RAIS no setor público devido, entre outras razões, à cobertura dos dados (ALVES; SONOBE, 2018), mas, em contrapartida, como é um registro de todas as ocupações, o volume de informações pode ajudar nas comparações entre trabalhadores do mercado formal de cada município. A Tabela 5 apresenta os dados da RAIS relativos aos vínculos que apresentaram mais de 30 trabalhadores registrados no município de Piraquara e que estão declarados 
como pessoas com Ensino Superior, também considera a remuneração nominal média registrada, a jornada que é informada como carga horária contratual e o número de casos para cada ocupação.

\section{Tabela 5 - Remuneração de trabalhadores com Ensino Superior completo em Piraquara - RAIS 2018}

\begin{tabular}{|l|c|c|c|c|c|c|}
\hline \multirow{2}{*}{\multicolumn{2}{|c|}{ Ocupações }} & \multicolumn{6}{c|}{ Municipal } \\
\cline { 2 - 7 } & \multicolumn{3}{|c|}{ Remuneração } & \multicolumn{3}{c|}{ Jornada } \\
\cline { 2 - 7 } & Média & $\begin{array}{c}\text { Desvio } \\
\text { Padrão }\end{array}$ & $\mathbf{N}$ & Média & $\begin{array}{c}\text { Desvio } \\
\text { Padrão }\end{array}$ & N \\
\hline $\begin{array}{l}\text { Professor de Nível Médio no Ensino } \\
\text { Fundamental }\end{array}$ & $1.675,96$ & 672,07 & 97 & 20 & 0 & 97 \\
\hline Assistente administrativo & $3.136,48$ & 1607,35 & 48 & 40 & 0 & 48 \\
\hline $\begin{array}{l}\text { Professor de Nivel Superior do Ensino } \\
\text { Fundamental (Primeira a Quarta Série) }\end{array}$ & $3.246,59$ & 1185,50 & 859 & 20 & 0 & 859 \\
\hline Enfermeiro & $3.295,81$ & 1202,24 & 39 & 40 & 0 & 39 \\
\hline Psicólogo Social & $3.404,54$ & 1652,52 & 35 & 40 & 0 & 35 \\
\hline Dirigente Serviço Público Municipal & $4.087,36$ & 2019,20 & 31 & 40 & 0 & 31 \\
\hline Assistente social & $4.204,29$ & 2058,36 & 31 & 30 & 0 & 31 \\
\hline Médico Clínico & $10.516,91$ & 4689,92 & 37 & 31 & 10 & 37 \\
\hline
\end{tabular}

Fonte: RAIS (2018).

Os dados da Tabela 5 não são conclusivos, mas permitem observar alguns elementos que são desafios para a equiparação salarial. O primeiro destaque é sobre a questão da jornada. É importante considerar os efeitos da jornada sobre os patamares remuneratórios bem como, não tirar a conclusão simples de que, dobrar a jornada dos professores significa dobrar a remuneração. Optou-se aqui, dado o caráter exploratório do exercício, por manter as médias desiguais. Uma solução poderia ser o cálculo de valor por hora de trabalho, entretanto, neste momento avaliou-se que explicitar as diferentes jornadas cumpre o papel de problematizar as diferenças no debate da remuneração.

A manutenção de jornadas de 20 horas para professores nas diferentes redes de ensino implica que, para cada jornada, o professor precisa fazer um concurso e, ao fazer isto, pode estar em lugares diferentes na carreira em cada um dos vínculos que assume. Além da imprecisão da questão da remuneração é importante considerar que mais de um vínculo tem implicações também nas condições de trabalho dos docentes. Mais de uma jornada pode exigir que o professor precise atuar em diferentes locais de trabalho; variar as escolas não tem apenas efeitos no deslocamento, o que é uma dimensão importante, mas também no envolvimento com o coletivo da escola e com a proposta pedagógica 
de cada local. Com as devidas ponderações em relação às dificuldades com a jornada, é possível observar na Tabela 5, uma proximidade entre a remuneração de professores, enfermeiros e psicólogo social, e uma distância muito acentuada de todas estas ocupações com a remuneração de médico clínico.

Esta é uma questão de fundo com relação ao status no mercado de trabalho. Outra questão para este debate do status é o volume de postos de trabalho do magistério, pelos dados declarados na RAIS, esta é a ocupação de Ensino Superior com maior número de trabalhadores empregados no município. O posto de médico também se relaciona a um direito de cidadania, porém pode-se ponderar a cobertura da saúde no âmbito municipal? De toda forma, professores e médicos têm o mesmo nível de escolaridade, o que implica enfrentar-se o desafio de valorizar o profissional ao mesmo tempo em que se garante a expansão do direito à educação.

\section{CONSIDERAÇÕES FINAIS}

O objetivo desse artigo foi analisar as condições de valorização dos professores no contexto municipal de Piraquara, a partir do bloco de metas do PNE e PME, voltado à valorização. Por considerar que a valorização docente é um princípio constitucional que se efetiva por meio da carreira, o ponto de partida foi analisar a efetividade do plano de carreira do município (meta 18), bem como as condições de formação (metas 15 e 16) e remuneração (meta 17). Para essa discussão é importante aproximar o debate entre a política de valorização docente e o financiamento da educação, uma vez que se parte da compreensão de que os elementos do financiamento, como vinculação de recursos, divisão de responsabilidades e definição de MDE, interferem nas condições de valorização dos professores.

Entre os desafios do contexto municipal de Piraquara frente às metas de valorização, tem-se a entrada na carreira ainda com exigência em nível médio, na modalidade normal, o desafio está em valorizar a formação inicial dos professores que ingressam na rede já com graduação ou pós-graduação, uma vez que permanecerão no nível I da tabela salarial, com vencimento igual ao de nível médio, durante os três anos de estágio probatório, para então ter o vencimento de acordo com sua formação/titulação. É positivo destacar que, embora a formação mínima exigida para ingresso na carreira seja de nível médio, na modalidade normal, o percentual de professores com graduação e pós-graduação é predominante na rede. 
No que diz respeito à formação continuada, mesmo o PME não determinando uma porcentagem de professores a serem formados na pósgraduação e não apresentando estratégias concretas para a pós-graduação e formação continuada em serviço, assim como faz o PNE, é relevante o número de professores com especialização que, no ano de 2018 , estava em $46,9 \%$, muito próximo da meta nacional de formar $50 \%$ de professores na especialização.

A meta 17, que trata da equiparação salarial, apresenta limites em sua avaliação no contexto municipal, a opção foi utilizar os dados da RAIS (2018) que demonstraram que há uma distância muito acentuada entre a remuneração dos professores e dos médicos, que possuem o mesmo nível de formação, situação essa que não é exclusiva do caso de Piraquara e está relacionada com o prestígio social da profissão e com o volume dos postos de trabalho.

No que se refere ao plano de carreira, a opção foi verificar sua efetividade em relação à abrangência e movimentação da carreira que, no caso analisado, acontece por meio da formação e do tempo de serviço e está condicionada à avaliação da prática profissional como garantia das elevações. Nessa meta, o grande desafio está em cumprir integralmente a lei do PISO no que se refere à jornada de trabalho destinada à hora-atividade, que ainda não chegou a 1/3 no município.

Ao final, é possível notar que o PNE, de certo modo, organizou a agenda nacional e local no que diz respeito aos elementos da política de valorização, ao estabelecer um bloco de metas exclusivo para tratar da formação - inicial e continuada, remuneração e carreira. Logo, é necessária a ampliação de recursos para a área de educação, conforme prevê a meta 20 do PNE, que aponta 10\% dos recursos do PIB, sobretudo, em um contexto nacional de ajuste fiscal que pode induzir e legitimar políticas de austeridade no contexto municipal.

\section{REFERÊNCIAS}

ALVES, T.; SONOBE, A. K. . Remuneração média como indicador da valorização docente no mercado de trabalho. Cadernos de Pesquisa (FUNDAÇÃO CARLOS CHAGAS. ONLINE), v. 48, p. 446-476, 2018.

ALVES, T. PINTO, J. M. R. Remuneração e características do trabalho docente no Brasil: um aporte. Cadernos de pesquisa, 2011, p. 606-639.

ARAÚJO, L. Impacto financeiro da implantação do caqi no brasil. Educação \& Sociedade, v. 40, p. 1-22, 2019. 
AMARAL. N. C. Com a PEC 241/55 (EC 95) haverá prioridade para cumprir as metas do PNE (2014-2024)?. Revista Brasileira de Educação, v. 22, n. 71, 2017.

BRASIL. Constituição (1988). Constituição: República Federativa do Brasil. Brasília, DF: Senado Federal, 1988.

BRASIL. Emenda Constitucional no 95, de 15 de Dezembro de 2016. Altera o Ato das Disposições Constitucionais Transitórias, para instituir o Novo Regime Fiscal, e dá outras providências. Diário Oficial da União, Brasília, DF, 2016.

BRASIL. Lei $\mathrm{n}^{\circ}$ 11.494, de 20 de junho de 2007. Regulamenta o Fundo de Manutenção e Desenvolvimento da Educação Básica e de Valorização dos Profissionais da Educação - FUNDEB. Diário Oficial da União, Brasília, DF, 1996.

BRASIL. Lei no 11.738 , de 16 de julho de 2008. Institui o piso salarial profissional do magistério público de educação básica. Diário Oficial da União, Brasília, DF, 2008.

BRASIL. Lei No 13.005, de 25 de junho de 2014. Aprova o Plano Nacional da Educação (PNE). Diário Oficial da União, Brasília, DF, 2008.

BRASIL. Lei no 9394, de 20 de dezembro de 1996. Estabelece as Diretrizes e Bases da Educação Nacional. Diário Oficial da União, Brasília, DF, 1996.

BRASIL. Relatório do $2^{\circ}$ Ciclo de Monitoramento das metas do Plano Nacional de Educação - 2018. Disponível em: < http://portal.inep.gov.br/ informacao-da-publicacao/-/asset_publisher/6JYIsGMAMkW1/document/ id/6725829.> Acesso em 29.jan.2020.

CARISSIMI, A. C. V. Ação sindical na construção da agenda política: um estudo sobre as reivindicações e negociações da APP-sindicato com os governos entre os anos de 2003 e 2015. Tese (Mestrado em Educação), Universidade Federal do Paraná, 2016.

CELLARD, A. A análise documental. In: POUPART, J, DESLAURIERS, J.; LAPERRIÈRE, A.; MEYER, R.; PIRES, A. P. A pesquisa qualitativa: Enfoques epistemológicos e metodológicos. Petrópolis, RJ: Vozes, 2008. 
COSTA, J. T. de P.; COELHO, C. L; OLIVEIRA, R de F. A Implementação do Piso Salarial Profissional Nacional em Minas Gerais: entre o dito, o feito e o escrito. Revista de Financiamento da Educação, v. 10, n. 3, 2020.

DOURADO, L. F. Plano Nacional de Educação: o epicentro das políticas de estado para educação brasileira. Goiânia: Editora Imprensa Universitária, ANPAE, 2017.

DUARTE, José B. Estudos de caso em educação. Investigação em profundidade com recursos reduzidos e outro modo de generalização. Revista Lusófona de Educação [em linha], p. 113-132, 2008. Disponível em: https://www.redalyc. org $/$ articulo.oa?id $=34911875008$

FERNANDES, M. D. E.; FERNANDES, S. J.; CAMPO, V. G. Remuneração docente: efeitos do plano de cargos, carreira e remuneração em contexto municipal. Ensaio (RIO DE JANEIRO. ONLINE), v. 28, p. 20-44, 2020.

FRANÇA, M.; SILVA, A. F. Valorização Docente no Plano Nacional de Educação (2014-2024): Tensões e conflitos no seu financiamento. In: FRANCA, Magna; BARBOSA JUNIOR, Walter P. (orgs). Políticas e Práxis educativas. Natal: Caule de Papiro, 2017.

GOUVEIA, A. B.; Fernandes, M. D. E. Agenda sindical de professores da Educação Básica: desafios postos a partir do Piso Salarial Profissional Nacional. Práxis Educativa, (UEPG. ONLINE), v. 14, p. 1-15, 2019.

GROCHOSKA, M. A. Políticas educacionais e a valorização do professor: carreira e qualidade de vida dos professores de educação básica do município de São José dos Pinhais/PR. Tese (Doutorado em Educação), Universidade Federal do Paraná, Curitiba, 2015.

HECK, B. T. M. Carreira de trabalhadoras docentes da Educação Infantil e o reconhecimento social como dimensão da valorização profissional. Tese (Doutorado em Educação). Universidade Federal do Paraná, Curitiba, 2019.

JACOMINI, M.; ALVES, T.; CAMARGO, R. B. de. Remuneração Docente: Desafios para o Monitoramento da Valorização dos professores brasileiros no contexto da Meta 17 do Plano Nacional de Educação. Arquivos Analíticos de Políticas Educativas, v.24, n. 73, 2016. 
NASCIMENTO. A. P. S. do. Carreira docente nas creches das redes públicas das capitais brasileiras: análise dos planos e estatutos do magistério. Tese (Doutorado Em Educação). Faculdade de Educação da Universidade de São Paulo, São Paulo, 2019.

OGIBA, S. M. Direito à educação, políticas de Estado: monitorando o PNE - Lei n ${ }^{\circ}$ 13005/2014.In: OGIBA, Sônia Mara M..(organizadora). Garantia do Direito à Educação: monitorando o PNE Lei no 13.005/2014. Porto Alegre: Editora da UFRGS, 2018.

OLIVEIRA, D. A profissão docente no contexto da Nova Gestão Pública no Brasil. In: OLIVEIRA et all (orgs). Políticas Educacionais e a reestruturação da profissão do educador: Perspectivas globais e comparativas. Petrópolis: Vozes, 2019.

PINTO, J. M. R.. O financiamento da educação no governo Lula. Revista Brasileira de Política e Administração da Educação, v. 25, p. 323-340, 2009.

PIRAQUARA. Lei Municipal No 1192/2012 DE 03 DE JULHO DE 2012. Estabelece o Plano De Cargos, Empregos, Carreira, Vencimentos e Salários Do Magistério Público Do Município De Piraquara.

PIRAQUARA. Lei Municipal $\mathbf{N}^{\mathbf{0}}$ 1491/2015, Institui o Plano Municipal de Educação do Município de Piraquara - PME e dá outras providências. Disponível em: <https://leismunicipais.com.br/a/pr/p/piraquara/leiordinaria/2015/149/1491/lei-ordinaria-n-1491-2015-institui-o-plano-municipalde-educacao-do-municipio-de-piraquara-pme-e-da-outras-providencias $>$ Acesso em: 29.jan.2020.

SILVA. M. Q. da. Remuneração dos professores públicos municipais no Brasil: execução orçamentária, partidos políticos e valorização docente (2008 - 2016). Tese (Doutorado em Educação). Universidade Federal do Paraná, Curitiba, 2019. 


\section{Daniele Meira Cordeiro}

Mestranda da linha de Políticas Educacionais do Setor de Educação da Universidade Federal do Paraná (UFPR). Pedagoga licenciada pela UFPR (2014). Professora efetiva da rede municipal de educação de Piraquara/Pr. E-mail: meira. dani@hotmail.com

\section{Andréa Barbosa Gouveia}

Possui graduação em Pedagogia pela Universidade Federal do Paraná (1995), mestrado (2002) e doutorado (2008) em Educação pela Universidade de São Paulo, Faculdade de Educação, na área de concentração Estado, Sociedade e Educação. Atualmente é professora da Universidade Federal do Paraná onde atua no Núcleo de pesquisa em Políticas Educacionais (NUPE). É professora do curso de Pedagogia. Está credenciada no Programa de Pós Graduação em Educação da UFPR na linha de pesquisa em Políticas Educacionais. E-mail: andrea-gouveia@uol.com.br

Recebido em: 22/06/2020

Aceito em: 24/11/2020 